\title{
Short communication: Field data reveal that the transport probability of clasts in Peruvian and Swiss streams mainly depends on the sorting of the grains
}

\author{
Fritz Schlunegger, Romain Delunel, and Philippos Garefalakis \\ Institute of Geological Sciences, University of Bern, 3012 Bern, Switzerland \\ Correspondence: Fritz Schlunegger (schlunegger@geo.unibe.ch)
}

Received: 7 December 2019 - Discussion started: 2 January 2020

Revised: 23 June 2020 - Accepted: 22 July 2020 - Published: 31 August 2020

\begin{abstract}
We present field observations from coarse-grained streams in the Swiss Alps and the Peruvian Andes to explore the controls on the probability of material entrainment. We calculate shear stress that is expected for a mean annual water discharge and compare these estimates with grain-specific critical shear stresses that we use as thresholds. We find that the probability of material transport largely depends on the sorting of the bed material, expressed by the $D_{96} / D_{50}$ ratio, and the reach gradient but not on mean annual discharge. The results of regression analyses additionally suggest that among these variables, the sorting exerts the largest control on the transport probability of grains. Furthermore, because the sorting is significantly correlated neither to reach gradient nor to water discharge, we propose that the granulometric composition of the material represents an independent, yet important control on the motion of clasts in coarse-grained streams.
\end{abstract}

\section{Introduction}

It has been proposed that the transport of coarse-grained material in mountainous streams occurs when flow strength - or bed shear stress - exceeds a grain-size-specific critical shear stress (Miller et al., 1977; Tucker and Slingerland, 1997; Church, 2006). This has been documented based on flume experiments (e.g., Meyer-Peter and Müller, 1948; Dietrich et al., 1989; Carling et al., 1992; Ferguson, 2012; Powell et al., 2016) and field observations (e.g., Paola and Mohring, 1996; Lenzi et al., 2006; Mueller et al., 2005; Lamb et al., 2008), and related concepts have been employed in theoretical models (Paola et al., 1992; Tucker and Slingerland, 1997). Whereas flow strength is mainly a function of discharge, energy gradient and channel width (e.g., Slingerland et al., 1993; Hancock and Anderson, 2002; Pfeiffer and Finnegan, 2018; Wickert and Schildgen, 2019), the threshold shear stress itself has been considered to depend on grainspecific variables, such as grain size and the arrangement of clasts including hiding and protrusion effects (Carling, 1983; Parker, 1990; van den Berg and Schlunegger, 2012; Pfeiffer and Finnegan, 2018), but not on the shape of individ- ual grains (Carling, 1983) - or at least this variable plays a minor role only (Komar and $\mathrm{Li}, 1986$ ). In addition, the threshold shear stress has also been related to the reach gradient (Lamb et al., 2008; Turowski et al., 2011; Pfeiffer and Finnegan, 2018). Here, we provide field data from coarsegrained single-thread streams in the Swiss Alps and braided rivers in the Peruvian Andes to illustrate that amongst the various variables, the sorting of the grains exerts the largest control on the transport probability. The field sites are located close to water gauging stations so that we have good constraints on the streams' discharge in our analyses. We determined the grain size distribution of gravel bars at these locations and calculated, within a probabilistic framework using Monte Carlo simulations, the likelihood of sediment transport for a mean annual water discharge $Q_{\text {mean }}$ and for discharge percentiles. We explored whether the related flows are strong enough to shift the $D_{84}$ grain size, which is considered to build the sedimentary framework of gravel bars as recent flume experiments have shown (MacKenzie and Eaton, 2017; MacKenzie et al., 2018). We thus considered the mobilization of the $D_{84}$ grain size as a priori condition - and thus 
as a threshold - for a change in the sedimentary arrangement of the target gravels bars.

The braided character of streams in Peru, however, complicates the calculation of sediment transport probabilities mainly because water flows frequently in multiple active channels, and channel widths vary over short distances. For these streams, we selected reaches (ca. $100 \mathrm{~m}$ long) where several active braided channels merge to a single one, before branching again. We are aware that this could eventually bias the results towards a greater material mobility, mainly because flows in single-thread segments are likely to have a greater shear stress than in braided reaches where the same water runoff is shared by multiple channels.

\section{Methods and datasets}

\subsection{Entrainment of bedload material}

Sediment mobilization is considered to occur when bed shear stress $\tau$ exceeds a grain-size-specific threshold $\tau_{\mathrm{c}}$ (e.g., Paola et al., 1992) as follows:

$\tau>\tau_{\mathrm{c}}$

Threshold shear stress $\tau_{\mathrm{c}}$ for the dislocation of grains with size $D_{x}$ (see Sect. 2.3.1 for further specifications) can be obtained using Shields (1936) criteria $\phi$ for the entrainment of sediment particles:

$\tau_{\mathrm{c}}=\phi\left(\rho_{\mathrm{s}}-\rho\right) g D_{x}$,

where $g$ denotes the gravitational acceleration, and $\rho_{\mathrm{S}}$ $\left(2700 \mathrm{~kg} \mathrm{~m}^{-\mathrm{s}}\right)$ and $\rho$ denote the sediment and water densities, respectively.

Bed shear stress $\tau$ is computed through (e.g., Slingerland et al., 1993; Tucker and Slingerland, 1997)

$\tau=\rho g R S$.

Here, $S$ denotes the energy gradient, and $R$ is the hydraulic radius, which is approximated through water depth $d$ where channel widths $W>20 d$ (Tucker and Slingerland, 1997), which is the case here. The combination of expressions for (i) the continuity of mass including flow velocity $V$, channel width $W$, and water discharge $Q$,

$Q=V W d$

(ii) the relationship between flow velocity and channel bed roughness $n$ (Manning, 1891),

$V=\frac{1}{n} d^{2 / 3} S^{1 / 2}$

and (iii) an equation for Manning's roughness number $n$ (Jarrett, 1984),

$n=0.32 S^{0.38} d^{-1 / 6}$, yields a relationship where bed shear stress $\tau$ depends on reach gradient, water discharge and channel width (Litty et al., 2017).

$\tau=0.54 \rho g\left(\frac{Q}{W}\right)^{0.55} S^{0.935}$

This equation is similar to the expression by Hancock and Anderson (2002), Norton et al. (2016), and Wickert and Schildgen (2019) with minor differences regarding the exponent on the channel gradient $S$ and on the ratio $Q / W$. These are mainly based on the different ways of how bed roughness is considered. Note that this equation does not consider a roughness length scale (both vertical and horizontal) because we have no constraints on this variable.

We explored whether Eq. (5) could be solved using the Darcy-Weisbach friction factor $f$ instead of Manning's $n$. According to Ferguson (2007), the friction factor $f$ varies considerably between shallow- and deep-water flows and depends on grain size $D_{x}$ relative to water depth $d$ and, thus, on the relative roughness. Ferguson (2007) developed a solution referred to as the variable power equation (VPE), which accounts for the dependency of $f$ on the relative importance of roughness-layer versus skin friction effects and thus on the $D_{x} / d$ ratios (see also Bunte et al., 2013). Calculations where the VPE was employed indeed revealed that roughness-layer effects have an impact on flow regimes where $D_{84} / d>0.2$ (Schlunegger and Garefalakis, 2018), which is likely to be the case in our streams. However, similar to Litty et al. (2016), we are faced with the problem that we have not sufficient constraints to analytically solve Eq. (5) with the VPE. We therefore selected Mannings's $n$ instead, which allowed us to solve this equation analytically.

\subsection{Monte Carlo simulations}

Predictions of sediment transport probability are calculated using Monte Carlo simulations performed within a MATLAB computing environment. We conducted 10000 simulations, and the results are reported as the probability (in percent) of $\tau>\tau_{\mathrm{c}}$ (Eq. 1). All variables that are considered for the calculations of both shear and critical shear stress (Eqs. 7 and 2, respectively) are randomly selected within their possible ranges of variation (Table 1). Except for the Shields variable $\phi$ that we consider to follow a uniform distribution between 0.03 and 0.06 (see Sect. 2.3.1 for justification), we infer that all other variables follow normal distributions, defined by their means and corresponding standard deviations.

To ensure that no negative values introduce a bias to these iterations, only strictly positive values for channel widths and gradients are considered. In the case of water discharge, both null and positive values are kept for further calculations. Values excluded from the calculations, i.e., returning negative water discharge or null or negative channel width-slope gradient, yield "NaN" in the resulting vector. For each of the 10000 iterations, $\tau$ and $\tau_{\mathrm{c}}$ are compared, which yields either 
" 1 " $\left(\tau>\tau_{\mathrm{c}}\right)$ or " 0 " $\left(\tau \leq \tau_{\mathrm{c}}\right)$. The sediment transport probability is then calculated as the sum of ones divided by the number of draws, from which the number of "NaN" values was subtracted before. Note that $<2500$ "NaN" were obtained for Rio Chico (PRC-ME17), which we mainly explain by the ca. $150 \%$ relative standard deviation of the mean annual water discharge estimated for that river.

\subsection{Parameters, datasets, uncertainties and sensitivity analyses}

\subsubsection{Shields variable $\phi$ and threshold grain size}

Assignments of values to $\phi$ vary and diverge between flume experiments (e.g., Carling et al., 1992; Ferguson, 2012; Powell et al., 2016) and field observations (Mueller et al., 2005; Lamb et al., 2008). Here, we considered that at the incipient motion of $D_{84}$, the Shields variable $\phi$ is equally distributed between 0.03 and 0.06 (Dade and Friend, 1998) during the 10000 iterations. We also explored a slope-dependency of $\phi$ (Lamb et al., 2008; Bunte et al., 2013; Pfeiffer et al., 2017; Pfeiffer and Finnegan, 2018), where

$\phi=0.15 S^{0.25}$.

However, applying this slope-dependent characterization of $\phi$ did not change our overall finding that the transport probability is dependent on the sorting of the material (Fig. S1 in the Supplement). In the same context, Turowski et al. (2011) reported a larger variation in the threshold conditions for the mobilization of clasts than those employed here. However, their streams have energy gradients between 0.06 and 0.1 , with the consequence that some of the material is entrained during torrential floods. The related conditions thus differ from those of the much flatter streams (reach gradients $<0.02$ ), which we explored in this paper. Finally, we did not explicitly include a grain-size specific hiding (e.g., Eq. A8 in Pfeiffer and Finnegan, 2018) or a protrusion function (e.g., Carling, 1983; Sear, 1996; van der Berg and Schlunegger, 2012) in our analysis, but we suggest that the selected range between 0.03 and 0.06 considers most of the complexities and scatters of $\phi$ values that are related to the hiding of small clasts and the protrusion of large constituents (Buffington et al., 1992; Buffington and Montgomery, 1997; Kirchner et al., 1990; Johnston et al., 1998). In summary, we infer that the selection of uniformly distributed $\phi$ values between 0.03 and 0.06 does account for the large variability of $\phi$ values that are commonly encountered in experiments and field surveys where energy gradients range between 0.001 and 0.02 , which is the case here.

We consider that the most important critical shear stress is that required to move $D_{84}$, rather than any other grain size percentile. We acknowledge that other authors preferentially selected the $D_{50}$ grain size as a threshold to quantify the minimum flow strengths $\tau_{\mathrm{c}}$ to entrain the bed material (e.g., Paola and Mohrig, 1996; Pfeiffer and Finnegan, 2018; Chen et al.,
2018). The selection of $D_{50}$ results in a lower threshold and a greater transport probability than the employment of $D_{84}$. However, among the various grain sizes, $D_{84}$ has been considered to best characterize the sedimentary framework of a gravel bar (Howard, 1980; Hey and Thorne, 1986; Grant et al., 1990), and more recent experiments have also shown that $D_{84}$ better characterizes the channel form stability than $D_{50}$ (MacKenzie et al., 2018). Accordingly, flows that dislocate the $D_{84}$ grain size are considered strong enough to alter the gravel bar architecture. We therefore followed the recommendation by MacKenzie et al. (2018) and selected the $D_{84}$ grain size to quantify the threshold conditions in Eq. (2).

\subsubsection{Grain size data}

We collected grain size data from streams where water discharge has been monitored during the past decades. These are the Kander, Lütschine, Rhein, Sarine, Simme, Sitter and Thur rivers in the Swiss Alps (Fig. 1a). The target gravel bars are situated close to a water gauging station. At these sites, five to six digital photographs were taken with a Canon EOS PR. The photos covered the entire lengths of these bars. A meter stick was placed on the ground and photographed together with the grains. Grain sizes were then measured with the Wolman (1954) method using the free software package ImageJ 1.52n (https://imagej.nih.gov, last access: 7 August 2019). Following Wolman (1954), we used intersecting points of a grid to randomly select the grains to measure. A digital grid of $20 \mathrm{~cm} \times 20 \mathrm{~cm}$ was calibrated with the meter stick on each photo. The size of the grid was selected so that the spacing between intersecting points was larger than the $b$ axis of most of the largest clasts (Tables 1 and S2 in the Supplement). The grid was then placed on the photograph with its origin at the lower-left corner of the photo. The intermediate or $b$ axis of approximately 250-300 grains (ca. 50 grains per photo; Table S2) underneath a grid point was measured for each gravel bar. In this context, we inferred that the shortest ( $c$ axis) was vertically oriented and that the photos displayed the $a$ and $b$ axes only. In cases where more than half of the grain appeared to be buried, the neighboring grain was measured instead. In the few cases where the same grain lay beneath several grid points, then the grain was only measured once. Only grains larger than a few millimeters $(>4$ $5 \mathrm{~mm}$, depending on the quality and resolution of the photos) could be measured. While the limitation to precisely measure the finest-grained particles potentially biases the determination of $D_{50}$, it will not influence the measurements of the $D_{84}$ and $D_{96}$ grain sizes, as the comparison between sieving and measuring of grains with the Wolman (1954) method has disclosed (Watkins et al., 2020). In addition, as will be shown below, the consideration of the $D_{96} / D_{84}$ instead of the $D_{96} / D_{50}$ ratios yields a similar positive relationship to the mobility of grains. We complemented the grain size datasets with published information on the $D_{50}, D_{84}$ and $D_{96}$ grain size (Litty and Schlunegger, 2017; Litty et al., 2017) for fur- 

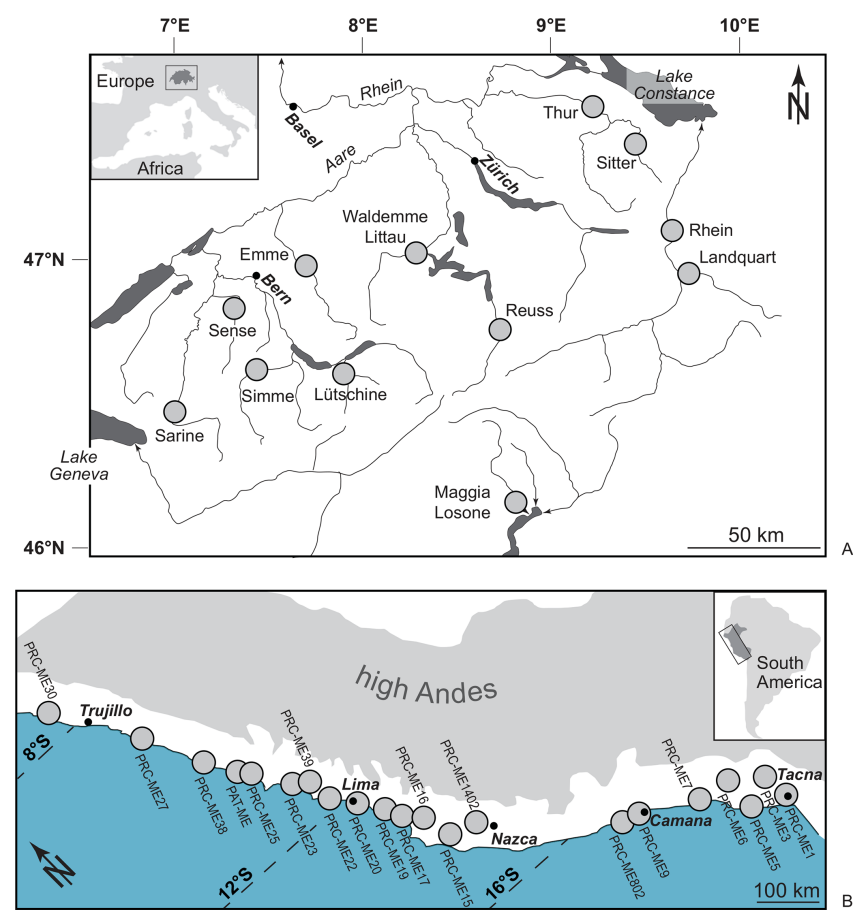

Figure 1. (A) Map showing the sites where grain size data have been measured in the Swiss Alps. The research sites are close to water gauging stations; (B) map showing locations for which grain size and water discharge data are available in Peru (Litty et al., 2017).

ther streams in Switzerland (six additional rivers) and Peru (21 sites) (Fig. 1a and b; Table 1). For a few streams in Switzerland, Hauser (2018) presented $D_{84}$ grain size data from the same gravel bars as Litty and Schlunegger (2017), but the photo was taken 1 year later and possibly from a different site. For these five locations, we took the arithmetic mean of both surveys (Table 1, data marked with c). All authors used the same approach upon collecting grain size data, which justifies the combination of the new with the published datasets.

We finally assigned an uncertainty of $20 \%$ to the $D_{84}$ threshold grain size, which considers the variability in $D_{84}$ within a gravel bar as the analysis of the intra-bar variation in $D_{84}$ for selected gravel bars in Switzerland shows (Table S2). The assignment of a $20 \%$ uncertainty to the $D_{84}$ threshold grain size also considers a possible bias that could be related to the grain size measuring technique (e.g., sieving in the field versus grain size measurements using the Wolman method; Watkins et al., 2020). However, it is likely to underestimate the temporal variability in the grain size data. Indeed, a repeated measurement on some gravel bars in Switzerland has revealed that up to 2-fold differences in grain size could be possible (Hauser, 2018).

\subsubsection{Water discharge data}

The Federal Office for the Environment (FOEN) of Switzerland has measured the runoff values of Swiss streams over several decades. We employed the mean annual discharge values over 20 years for these streams (Table S3) and calculated 1 standard deviation thereof (see Table 1). For the Peruvian streams, we used the mean annual water discharge values $Q_{\text {mean }}$ reported by Litty et al. (2017) and Reber et al. (2017). These authors obtained the mean annual water discharge (Table 1) through a combination of hydrological data reported by the Sistema Nacional de Información de Recursos Hídricos and the TRMM-V6.3B43.2 precipitation database (Huffman et al., 2007). They also considered the intra-annual runoff variability as 1 standard deviation from $Q_{\text {mean }}$ to account for the strong seasonality in runoff for the Peruvian streams, which we employed in this paper. For the Peruvian streams, the assigned uncertainties to $Q_{\text {mean }}$ are therefore significantly larger than for the Swiss rivers (Table 1). A reassessment of the interannual variability in water discharge for those streams in Peru where the gauging sites are close to the grain size sampling location (distance of a few kilometers) yields a 1 standard deviation of ca. 50\%, which is still much larger than for the Swiss rivers (Table S3). We therefore run sensitivity tests where we considered scenarios with different relative values for $1 \sigma$ standard deviations of $Q_{\text {mean }}$.

We additionally ran sensitivity tests to explore how the mobility probability changes if discharge quantiles instead of $Q_{\text {mean }}$ are considered (Table S4). We ran a series of Monte Carlo simulations for various discharge quantiles and then calculated the resulting probability of sediment mobilization for each of these quantiles. We then multiplied the occurrence probability of each discharge quantiles (listed by the Swiss authorities and calculated for the Peruvian streams based on 4 to 98 years equivalent daily records) with the corresponding transport probability and summed the values. This integration provides an alternative estimate of transport probability (Table S4).

\subsubsection{Channel width data}

For the Swiss streams, channel widths and gradients (Table 1) were measured on orthophotos and lidar DEMs with a $2 \mathrm{~m}$ resolution provided by Swisstopo. From this database, gradients were measured over a reach of ca. 250 to $500 \mathrm{~m}$. All selected Swiss rivers are single-thread streams following the classification scheme of Eaton et al. (2010), and flows are constrained by artificial banks where channel widths are constant over several kilometers. For these streams, we therefore measured the cross-sectional widths between the channel banks, similar to Litty and Schlunegger (2017).

We complemented this information with channel width (wetted perimeter) and energy gradient data for 21 Peruvian streams that were collected by Litty et al. (2017) in the field 


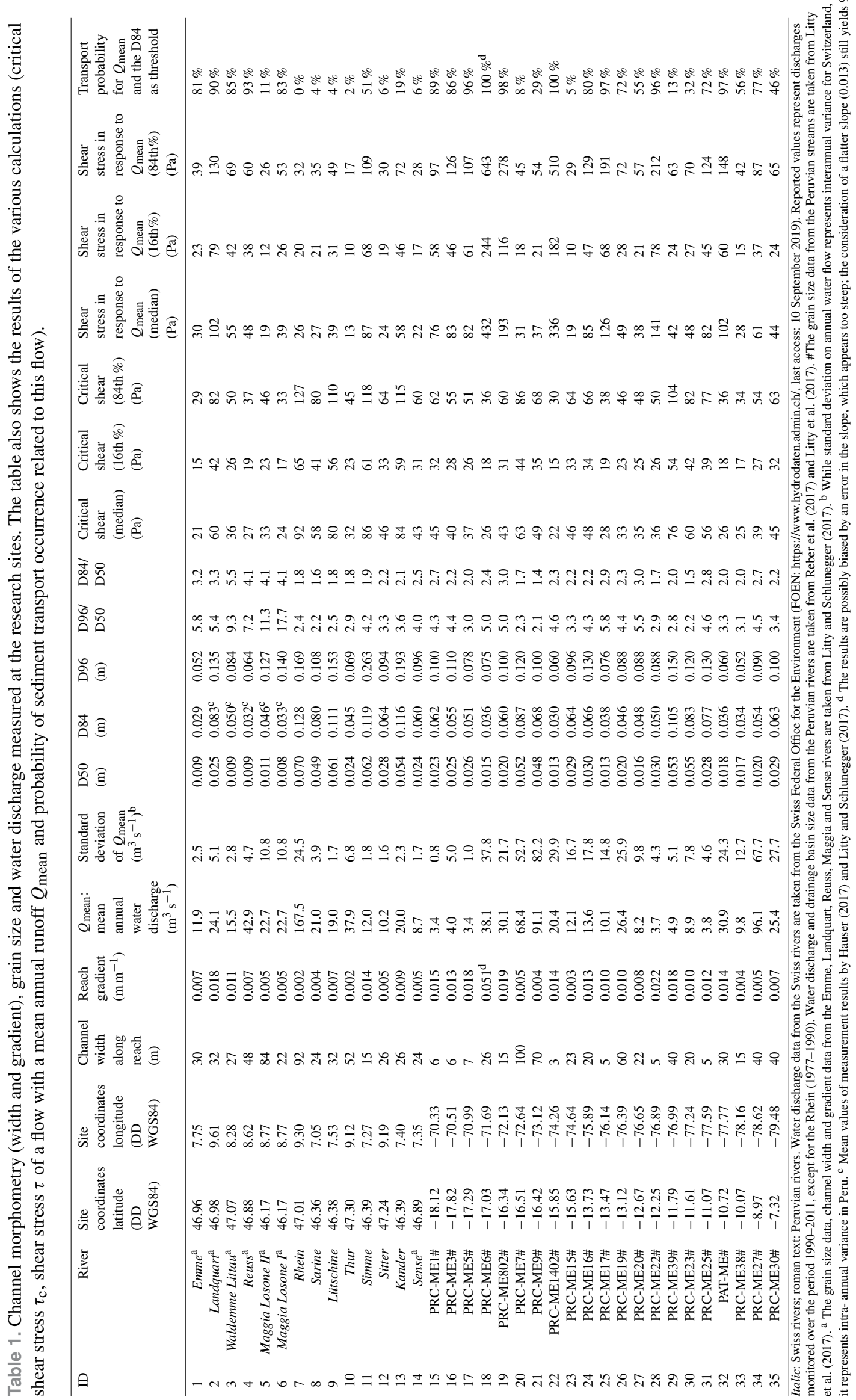


and on orthophotos taken between March and June. This period also corresponds to the season when the digital photos for the grain size analyses were made (May 2015). We acknowledge that widths of active channels in Peru vary greatly on an annual basis because of the strong seasonality of discharge (see above and large intra-annual variability in discharge in Table 1). We therefore considered scenarios where channel widths are twice as large as those reported in Table 1.

The uncertainties on reach gradient and channel width largely depend on the resolution of the digital elevation models underlying the orthophotos ( $2 \mathrm{~m}$ lidar DEM for Switzerland and $30 \mathrm{~m}$ ASTER DEM for Peru). It is not possible to precisely determine the uncertainties on the gradient values. Nevertheless, we anticipate that these will be smaller for the Swiss rivers than for the Peruvian streams mainly because of the higher resolution of the DEM. We ran sensitivity models where we explored how the probability of material transport changes in the Swiss rivers for various uncertainties on channel widths, energy gradients and mean annual discharge values.

\section{Results}

\subsection{Grain size data, critical and bed shear stress, and transport probability}

The grain sizes range from 8 to $70 \mathrm{~mm}$ for $D_{50}, 29$ to $128 \mathrm{~mm}$ for $D_{84}$ and 52 to $263 \mathrm{~mm}$ for $D_{96}$. The smallest and largest $D_{50}$ values were determined for the Maggia and Rhein rivers in the Swiss Alps, respectively (Table 1). The grain sizes in the Swiss rivers also reveal the largest spread where the ratio between the $D_{96}$ and $D_{50}$ grain size ranges between 2.2 (Sarine) and 17.7 (Maggia Losone I), while the corresponding ratios in the Peruvian streams are between 2.1 (PRCME9) and 5.8 (PRC-ME17). In the Swiss Alps, the critical shear stress values $\tau_{c}$ (median) for entraining the $D_{84}$ grain size range from ca. $20 \mathrm{~Pa}$ (Emme river) to ca. $90 \mathrm{~Pa}$ (Rhein and Simme rivers). In the Peruvian Andes, the largest critical shear values are $<80 \mathrm{~Pa}$ (PRC-ME39). The shear stress values related to the mean annual water discharge $Q_{\text {mean }}$ range from ca. 15 to $100 \mathrm{~Pa}$ in the Alps and from 20 to $>400 \mathrm{~Pa}$ in the Andes. Considering the strength of a mean annual flow and the $D_{84}$ grain size as threshold, the probability of sediment transport occurrence in the Peruvian Andes and in the Swiss Alps comprises the full range between $0 \%$ and $100 \%$.

Rivers that are not affected by recurrent high-magnitude events (e.g., debris flows) and where the grain size distribution is not perturbed by lateral material supply are expected to display a self-similar grain size distribution (Whittaker et al., 2011; D' Arcy et al., 2017; Harries et al., 2018), characterized by a linear relationship between the $D_{84} / D_{50}$ and $D_{96} / D_{50}$ ratios. In case of the Maggia river, the largest grains are oversized if $D_{50}$ and the grain size distribution of the other streams are considered as reference (Fig. 2a). This could reflect a response to the supply of coarse-grained ma-

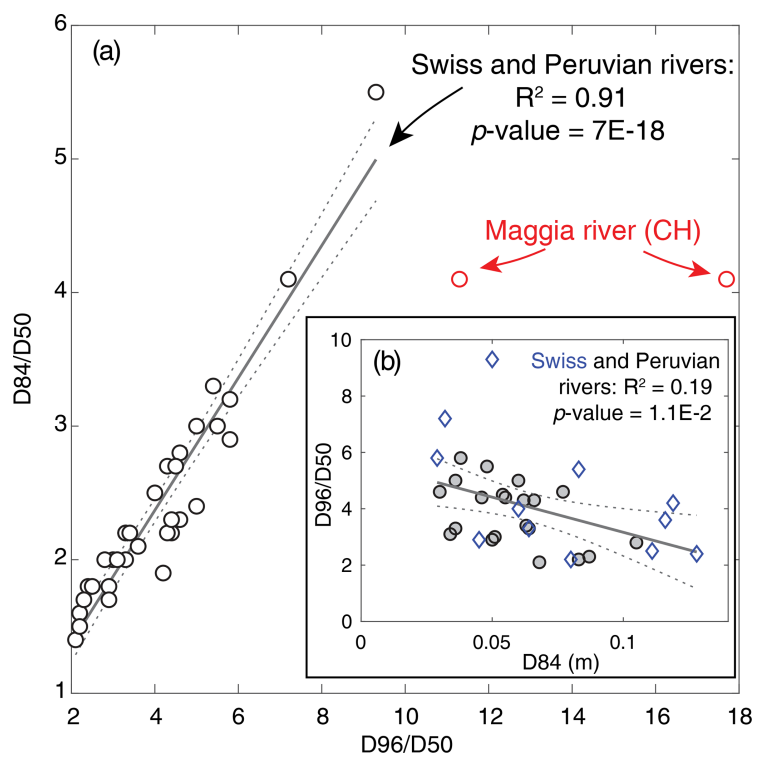

Figure 2. (a) Relationship between ratio of the $D_{96} / D_{50}$ and $D_{84} / D_{50}$, implying that the $D_{96}$ grain sizes of the Maggia gravel bars are too large if the $D_{50}$ is taken as reference and if the other gravel bars are considered. (b) Relationships between $D_{84}$ and sorting, expressed by the $D_{96} / D_{50}$ ratio. The Maggia data are not considered in this figure. However, the negative correlation between these variables is weak. Blue diamonds correspond to the Swiss rivers, while grey circles are Peruvian ones.

terial by a tributary stream where the confluence is $<1 \mathrm{~km}$ upstream of the Maggia sites. Alternatively - and possibly more likely - it reflects the response to the high-magnitude floods in this stream (Brönnimann et al., 2018) that could explain why the largest grains tend to be oversized. In particular, while the ratio between the last and first quantiles of discharge is $<150$ in the Swiss streams on the northern side of the Alps, the ratio is 860 in the Maggia river. Such ratios are not rare in Peru. However, the Peruvian streams appear to have adapted to such a large discharge variability through their network of braided channels that are not confined by artificial banks along most of the streams. In either case, because the grains in the Maggia river have a different size composition than the other streams (Fig. 2a), we excluded the Maggia data from further analyses. From this dataset, we then explored whether $D_{84}$ depends on the sorting of the grains $\left(D_{96} / D_{50}\right.$ ratio), but a possible negative correlation between these variables is very weak $\left(R^{2}=0.2\right)$ with a $p$-value of 0.011 (Fig. 2b).

\subsection{Correlations between channel metrics, water discharge, material sorting and transport probability}

The probability of sediment transport occurrence correlates positively with the reach gradient $\left(R^{2}=0.46, p\right.$-value $=$ 0.016 for Swiss rivers; $R^{2}=0.34, p$-value $=0.0056$ for streams in Peru; Fig. 3a). For the Peruvian rivers, the proba- 
bility of occurrence also scales negatively with channel width $\left(R^{2}=0.37, p\right.$-value $=0.0033 ;$ Fig. $\left.3 \mathrm{~b}\right)$ and critical shear stress $\tau_{\mathrm{c}}\left(R^{2}=0.48, p\right.$-value $=0.00047$; Fig. $\left.3 \mathrm{~d}\right)$, which itself depends on the threshold grain size $D_{84}$. No significant correlations are found between the transport probability and mean annual water discharge for the Swiss and Peruvian rivers (Fig. 3c).

Notably, the probability of material transport correlates positively and linearly with the $D_{96} / D_{50}$ ratio (Fig. 4a). The observed relationship appears stronger for the Swiss rivers $\left(R^{2}=0.76\right)$, than for the Peruvian streams $\left(R^{2}=\right.$ 0.36 ), and both correlations are significant with $p$-values of 0.00022 and 0.0041 , respectively. These correlations suggest that poorer-sorted bed material, here expressed by a high $D_{96} / D_{50}$ ratio, has a greater transport probability than better-sorted sediments. If the normalized residuals are plotted against the sorting, then they do not show any specific and significant patterns and, therefore, appear independent of the sorting (Fig. 4b). This suggests that the inferred linear relationships between the transport probability and the $D_{96} / D_{50}$ ratio are statistically robust. Although Fig. $4 \mathrm{a}$ implies that the regression for the Swiss rivers (slope: $0.16 \pm 0.06$; intercept: $-0.34 \pm 0.31$ ) differs from that of the Peruvian streams (slope: $0.18 \pm 0.11$; intercept: $-0.02 \pm 0.46$ ), the regression parameters do not significantly differ when considering them within their $95 \%$ confidence intervals. In addition, sites with larger values of $D_{96} / D_{50}$ tend to be associated with smaller values of $D_{84}$ (albeit with a weak correlation), but as noted earlier the influence of $D_{84}$ on the critical shear stress is not sufficient to explain the observed relationship between mobility and $D_{96} / D_{50}$ in the Swiss streams.

Because the sorting itself could potentially depend on channel metrics and water discharge, we explored possible correlations between these variables. We find that the $D_{96} / D_{50}$ ratio negatively correlates with channel widths for Peruvian streams $\left(R^{2}=0.20, p\right.$-value $\left.=0.040\right)$ but not with any of the other variables in both mountain ranges (e.g., reach gradient, mean annual discharge and discharge variability; see Fig. S5). In the same sense, the positive relationship between the $D_{96} / D_{50}$ ratio and the reach gradient in the Swiss rivers $\left(R^{2}=0.23\right)$ is statistically not significant ( $p$ value $=0.12$ ). As mentioned above, the $D_{96} / D_{50}$ ratio negatively correlates with $D_{84}$, but the correlation is weak and explains $20 \%$ of the observations only (Fig. 2b).

\subsection{Discharge quantiles, uncertainties on reach slopes and channel widths}

The use of discharge quantiles yields sediment transport probabilities that are positively and linearly correlated with the transport probability estimated with $Q_{\text {mean }}$ (Fig. S4). In addition, the correlations are very similar between the Swiss (slope: $0.74 \pm 0.02$; intercept: $0.05 \pm 0.01$ ) and Peruvian streams (slope: $0.73 \pm 0.19$; intercept: $0.03 \pm 0.14$ ). The mean annual discharge estimates $Q_{\text {mean }}$ are likely biased by infrequent but large-magnitude floods, which could explain the $25 \%$ larger transport probabilities if $Q_{\text {mean }}$ is used as reference discharge.

The assignments of different uncertainties on reach gradients, channel widths and discharge have no major influence on the inferred relationships between transport probability and sorting (Tables S6 and S7). For the Peruvian streams, however, assignments of 2-fold-larger values to channel widths will decrease the transport probability for a given sorting by ca. $10 \%-15 \%$, consistent with Figs. $3 b$ and S5 that illustrate negative correlations between channel width, $D_{96} / D_{50}$ ratio and transport probability. The inferred linear relationship between both variables, however, will remain (Table S7).

\section{Discussion}

\subsection{Controls of channel metrics on the transport probability}

Our analysis documents a slope dependency of sediment transport probability for the Swiss and Peruvian streams. Such a relationship has been documented before for mountainous rivers in the USA (Torizzo and Pitlick, 2004; Pfeiffer and Finnegan, 2018) and for other sites including the Alps (Van den Berg and Schlunegger, 2012). Pfeiffer and Finnegan (2018) reported transport probabilities, at conditions of an annual flow, that range between $8 \%$ and nearly $100 \%$ for the west coast in the USA, $1 \%$ and $12 \%$ for the Rocky Mountains, and $<10 \%$ for the Appalachian Mountains. These estimates are generally lower than the probabilities reported here. This most likely reflects the effect of the low channel gradients of the US streams that are ca. 3 times flatter than the rivers analyzed here (Table 1). These differences thus emphasize the controls of the reach gradient on the entrainment probability of coarse-grained bed material.

The regression analysis also documents that channel widths and critical shear stress have an influence on the transport probability of clasts. This is particularly the case for the braided streams in Peru where wider channels and greater critical shear stresses tend to lower the transport probability (Fig. 3b, d). Since braided streams dynamically adjust their channel widths to changes in the caliber and the rates of the supplied material (Church, 2006), a dependency of transport probability on channel width and grain-size specific threshold (including $D_{84}$ ) was expected. The absence of corresponding relationships in the Swiss streams is probably due to the managed geometry of these streams where artificial banks constrain the channel widths over tens of kilometers.

\subsection{Controls of material sorting on the transport probability}

Interestingly, our regression analysis of the variables disclosed a positive correlation between the $D_{96} / D_{50}$ ratio of 

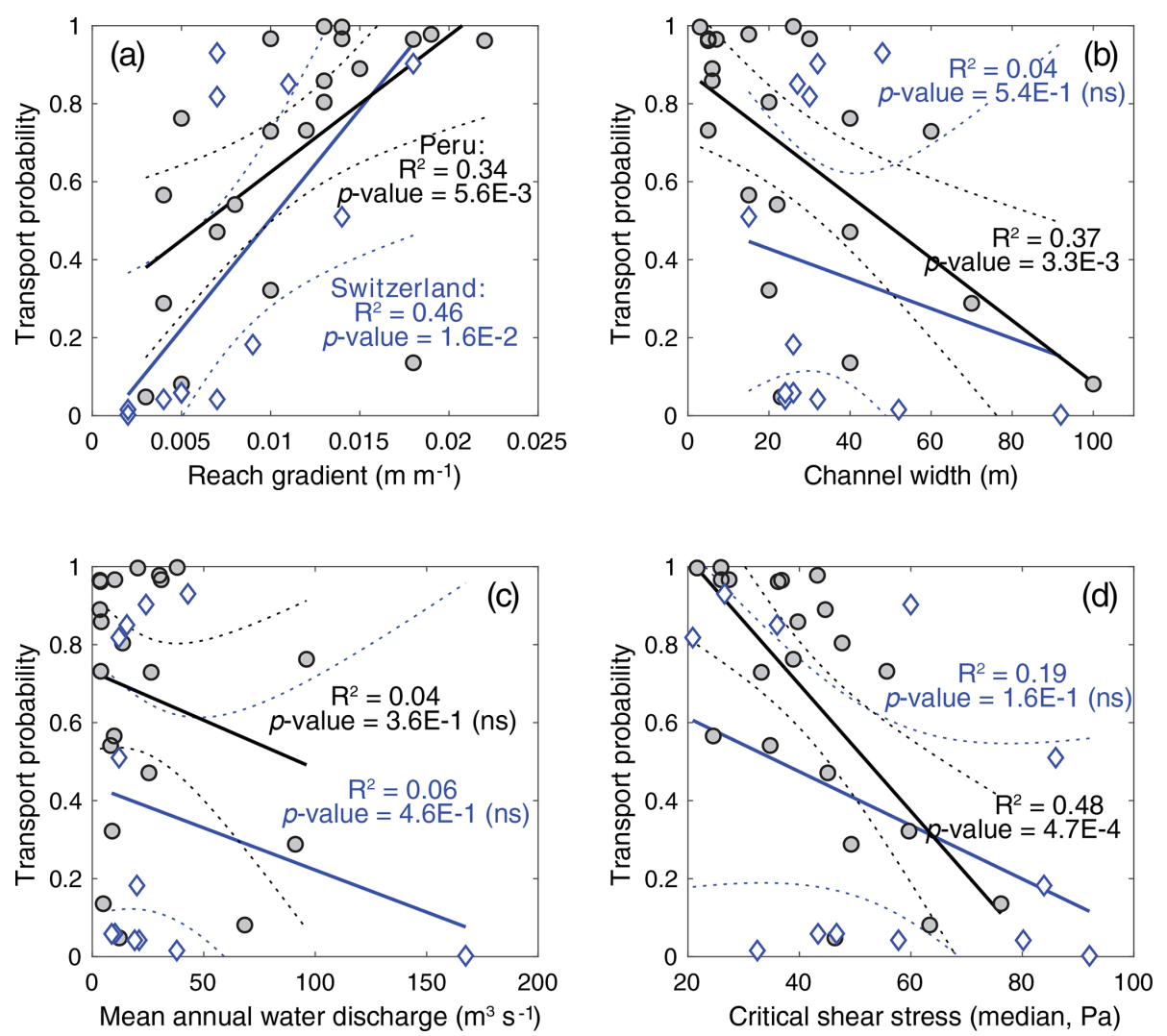

Figure 3. Relationships between transport probability and (a) reach gradient, (b) channel width, (c) mean annual discharge and (d) critical shear stress that depend on the $D_{84}$. Blue diamonds correspond to the Swiss rivers, while grey circles are Peruvian ones.

the bed material and the transport probability. This relationship maintains if transport probabilities are calculated based on discharge quantiles (Table S4) and if larger channel width and discharge variability particularly for Peruvian streams are considered (Table S7). Such a dependency will also remain if critical shear stress is calculated using a different grain size percentile. This is because grain size $D_{x}$ linearly propagates into the Eq. (2) and thus into the probability of $\tau>\tau_{\mathrm{c}}$. Therefore, although the resulting probabilities will adjust according to the threshold grain size, the relationships between the $D_{96} / D_{50}$ ratio and the mobilization probability will not change. Furthermore, because of the linear relationship between the $D_{84} / D_{50}$ and $D_{96} / D_{50}$ ratios (Fig. 2), the same dependency of transport probability on the sorting will also emerge if the $D_{96} / D_{84}$ ratios are used. This suggests that the sorting of the bed material has a measurable impact on the mobility of gravel bars and thus on the frequency of sediment mobilization irrespective of the selection of a threshold grain size. In addition, there appears to be a feedback where a poorer sorting (large $D_{96} / D_{50}$ ratio) tends to be associated with a lower $D_{84}$ (Fig. 2), which additionally increases the sediment transport probability. We note that while the data are relatively scarce and scattered (i.e., the same transport probability for a ca. 2-fold difference in the $D_{96} / D_{50}$ ratio), the relationships observed between the probability of transport occurrence and the degree of material sorting are significant with $p$-values $\ll 0.05$. Finally, for a given $D_{96} / D_{50}$ ratio, the probability of material transport tends to be greater in the Peruvian than in the Swiss rivers (Fig. 4a). We tentatively explain the apparent small divergence in the transport probability between both settings (i.e., regression parameters overlap within their $95 \%$ confidence interval) by the differences in the flow patterns (braided versus single-thread artificial channels).

\subsection{Controls on the sorting of the bed material}

None of the possible variables such as channel reach gradient, mean water discharge and discharge variability are significantly correlated with the bed material sorting (Fig. S5). Exceptions are the Peruvian streams where wider channels tend to be associated with a better sorting (i.e., lower $D_{96} / D_{50}$ ratio). We lack further quantitative information to properly interpret these patterns, but it appears that material sorting represents an additional yet independent variable that influences the probability of transport, at least for the sites we have investigated in this paper. Because the sorting of the bed material in the analyzed streams appears not to strongly depend on the hydrological conditions at the reach scale, it 

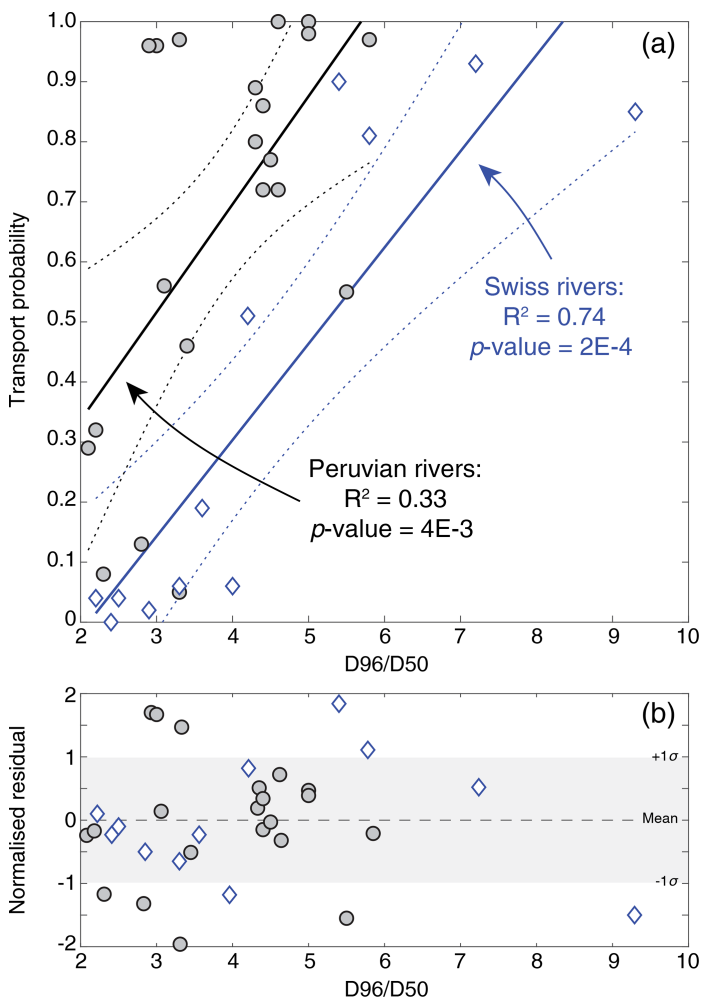

Figure 4. (a) Relationships between the probability of sediment transport occurrence and the $D_{96} / D_{50}$ ratio, which we use as proxy for the sorting of the gravel bar, in the Swiss and Peruvian rivers. (b) Normalized residuals that are plotted against the sorting. The normalized residuals do not show any specific and significant patterns. Blue diamonds correspond to the Swiss rivers, while grey circles are Peruvian ones.

could possibly reflect an inherited supply signal from further upstream (Pfeiffer et al., 2017). Indeed, detailed grain size analyses along fluvial gorges in the Swiss Alps have shown that the hillslope-derived supply of large volumes of sediment perturbs the granulometric composition of the bed material (van den Berg and Schlunegger, 2012; Bekaddour et al., 2013). Using the results of flume and numerical experiments, Jerolmack and Paola (2010) suggested that these source signals are likely to be shredded during sediment transport as a consequence of what they considered as ubiquitous thresholds in sediment transport systems. However, based on a detailed analysis of downstream fining trends in alluvial fan deposits, Whittaker et al. (2011), D'Arcy et al. (2017) and Brooke et al. (2018) proposed that primary source signals of grain size compositions are likely to propagate farther downstream in a self-similar way. Accordingly, the original grain-size sorting of the supplied material could be maintained although a general fining of the sediments along the sedimentary routing system would be observed. This idea could offer an explanation of why the $D_{96} / D_{50}$ ratios are to a large extent independent from other variables. It also points to the importance of sediment supply not only for control- ling the bankfull hydraulic geometry of channels (Pfeiffer et al., 2017) but also for the sorting of the material. Finally, a supply control could possibly explain why sorting appears to vary with $D_{84}$, albeit with a poor correlation, where a better sorting tends to be associated with larger $D_{84}$.

\subsection{Relative importance of sorting versus gradient on the transport probability}

Because gradient and sorting are independent variables and since the transport probability depends linearly on both variables, the transport probability can be described as a linear but weighted combination of gradient and sorting. We therefore assess whether the transport probability (Tp) in both the Swiss $(i=1)$ and the Peruvian $(i=2)$ rivers can be predicted using a multiple linear regression: $T p_{i}=\alpha_{i} S_{\mathrm{n}}+\beta_{i} G_{\mathrm{n}}+\delta_{i}$, where $S_{\mathrm{n}}$ and $G_{\mathrm{n}}$ are the sorting and gradient normalized to their respective maximum, and $\alpha, \beta$, and $\delta$ are the regression parameters. We decided to normalize both the sorting and gradient to their maximum values so that both variables vary on a similar [0-1] range, and the inferred linear coefficients $\alpha, \beta$ and $\delta$ can be directly compared between the Swiss and the Peruvian rivers. The model outputs show that when sorting and gradient are combined, then the predictions of the transport probability in both the Swiss $\left(R^{2}=0.85, p=\right.$ $\left.2.24 \times 10^{-4}\right)$ and the Peruvian $\left(R^{2}=0.61, p=1.9 \times 10^{-4}\right)$ rivers are significantly improved compared to simple linear regressions. The results also reveal that the relative importance of sorting on the transport probability is greater $(\alpha$ is $1.22 \pm 0.26$ for the Swiss streams and $1.46 \pm 0.41$ for the Peruvian streams) than the relative controls of reach gradient ( $\beta$ is $0.62 \pm 0.27$ for the Swiss streams and $0.67 \pm 0.20$ for the Peruvian rivers). The comparison of the estimated factors thus suggests that the relative importance of sorting on the transport probability could be twice as large as the controls of gradient, although our estimation is associated with large uncertainties (2.0 \pm 1.0 in Switzerland; $2.2 \pm 0.9$ in Peru). Interestingly, we also note that the apparent greater probability of transport in the Peruvian rivers, as we infer based on all simple linear regressions reported in Figs. 3 and 4, remains with our multiple linear regression analysis $(\delta$ is $-0.42 \pm 0.12$ for the Swiss streams and $-0.28 \pm 0.19$ for the Peruvian streams; Fig. 5). Again, this suggests that an additional component (intrinsic geomorphic setting such as, e.g., braided vs. single thread) may contribute to the observed higher probability of sediment transport in the Peruvian rivers than in the Swiss ones. The search for an answer to this questions, however, is beyond the scope of this paper and would require additional research.

\section{Conclusions}

We confirm the results of previous research that the transport probability of coarse-grained material in mountainous streams largely depends on the reach gradient. We also find 


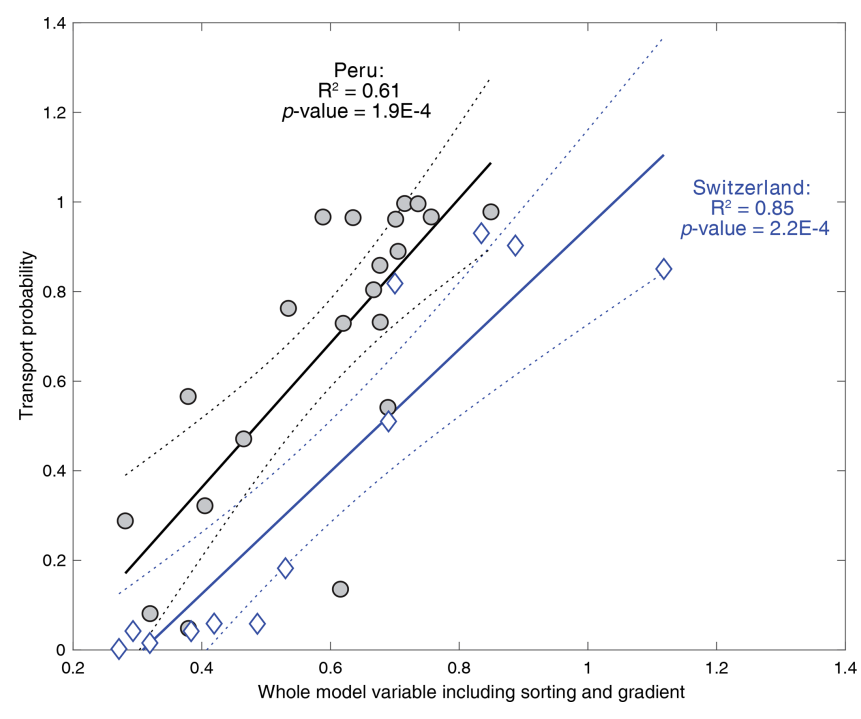

Figure 5. Transport probability for the Swiss and Peruvian rivers plotted as a function of the combined response to gradient and sorting. Blue diamonds correspond to the Swiss rivers, while grey circles are Peruvian ones. Both best multiple linear regression fits (solid line) and their $95 \%$ confidence intervals (dashed curves) are presented. Note that the variables on the axis are adjusted as a result of projecting the multiple linear regression models onto a bivariate plot.

a positive correlation between the $D_{96} / D_{50}$ ratio of the bed material and the transport probability where a poorer sorting of the material results in a larger probability of material entrainment. Despite the large scatter in the dataset, this relationship is statistically significant with $p$-values $\ll 0.05$, which suggests that the sorting of coarse-grained bed sediments has a measurable impact on the mobility of the bedload material. Regression analyses additionally reveal that sorting exerts a greater control on the transport probability than reach gradient. Furthermore, the lack of a significant correlation between reach gradient and sorting implies that both variables are largely independent from each other, at least for the investigated rivers in Switzerland and Peru. We therefore propose that the sorting of the bed material represents an additional, yet important variable that influences the mobility of material on gravel bars. Finally, we identify two main open questions that we cannot resolve with our dataset. First, Fig. 5 illustrates that $15 \%$ of the transport probability observations in Switzerland and $40 \%$ of the data in Peru cannot be fully explained by a combination of sorting and reach gradient, and interpretations thereof most likely require the consideration of the anthropogenic management of the streams (braided and free flow in Peru versus engineered single-thread channels in Switzerland). Second, we have not identified a significant correlation between the sorting and the other variables such as reach gradient, water discharge and discharge variability. This led us to propose that material supply need to be included in the discussion as well. Furthermore, the critical shear stress, through its dependency on $D_{84}$, is also a function of the sorting (albeit with a weak correlation; Fig. 2b). This could invoke a possible feedback where a poorer sorting tends to be associated with lower $D_{84}$ and thus with a lower critical shear stress, which further promotes the mobility of grains. We do not have the required data to fully address these latter two questions and suggest that it could serve as a topic in future research.

Data availability. All data that have been used in this paper are listed in Table 1 and in the Supplement.

Supplement. The supplement related to this article is available online at: https://doi.org/10.5194/esurf-8-717-2020-supplement.

Author contributions. FS and RD designed the study. RD conducted the Monte Carlo simulation. PG provided the grain size data in the Supplement. FS wrote the paper with input from RD and PG. All authors discussed the article.

Competing interests. The authors declare that they have no conflict of interest.

Acknowledgements. The Federal Office for the Environment (FOEN) is kindly acknowledged for providing runoff data for the Swiss streams. This research was supported by SNF (no. 155892). The constructive comments by Georgios Maniatis, two anonymous reviewers and the handling editor (Rebecca Hodge) are kindly acknowledged and significantly improved the science of this paper.

Financial support. This research has been supported by the Swiss National Science Foundation (grant no. 155892).

Review statement. This paper was edited by Rebecca Hodge and reviewed by Georgios Maniatis and two anonymous referees.

\section{References}

Bekaddour, T., Schlunegger, F., Attal, M., and Norton, K. P.: Lateral sediment sources and knickzones as controls on spatio-temporal variations of sediment transport in an Alpine river, Sedimentology, 60, 342-357, 2013.

Bunte, K., Abt, S. R., Swingle, K. W., Cenderelli, D. A., and Schneider, M.: Critical Shields values in coarse-bedded steep streams, Water Res. Res., 49, 7427-7447, 2013.

Brőnnimann, S., Rohr, C., Stucki, P., Summermatter, S., Bandhauer, M., Barton, Y., Fischer, A., Froidevaux, P., Germann, U., Grosjean, M., Hupfer, F., Ingold, K., Isotta, F., Keiler, M., Martius, O., Messmer, M., Mu“lchi, R., Panziera, L., Pfister, L., 
Raible, C. C., Reist, T., Ro“ssler, O., Ro“thlisberger, V., Scherrer, S., Weingartner, R., Zappa, M., Zimmermann, M., and Zischg, A. P.: 1968 - das Hochwasser, das die Schweiz veränderte. Ursachen, Folgen und Lehren für die Zunkunft, Geographica Bernensai, G94, Geographisches Institut der Universität Bern, Schweiz, 52 pp., 2018.

Brooke, S. A. S., Whittaker, A. C., Armitage, J. J., D’Arcy, M., and Watkins, S.: Quantifying Sediment Transport Dynamics on Alluvial Fans From Spatial and Temporal Changes in Grain Size, Death Valley, California, J. Geophys. Res.-Earth, 123, 20192067, https://doi.org/10.1029/2018JF004622, 2018.

Buffington, J., Dietrich, W. E., and Kirchner, J. W.: Friction angle measurements on a naturally formed gravel streambed: Implications for critical boundary shear stress, Water Res. Res., 28, 411425, 1992

Buffington, J. M. and Montgomery, D. R.: A systematic analysis of eight decades of incipient motion studies, with special reference to gravel-bedded rivers, Water Resour. Res., 33, 1993-2029, 1997.

Carling, P. A.: Threshold of coarse sediment transport in broad and narrow natural streams, Earth Surf. Process. Landf., 8, 1-18, 1983.

Carling, P. A., Kelsey, A., and Glaister, M. S.: Effect of bed roughness, particle shape and orientation on initial motion criteria, in: Dynamics of gravel-bed rivers, edited by: Billi, P., Hey, R. D., Throne, C. R., and Tacconi, P., 23-39, John Wiley and Sons, Ltd., Chichester, 1992.

Chen, C., Guerit, L., Foreman, B. Z., Hassenruck-Gudipati, H. J., Adatte, T., Honegger, L., Perret, M., Sluijs, A., and Castelltort, S.: Estimating regional flood discharge during Palaeocene-Eocene global warming, Sci. Rep., 8, 13391, https://doi.org/10.1038/s41598-018-31076-3, 2018.

Church, M.: Bed material transport and the morphology of alluvial river channels, Ann. Rev. Earth Planet. Sci., 34, 325-354, 2006.

Dade, B. and Friend, P. F.: Grain-size, sediment-transport regime, and channel slope in alluvial rivers, J. Geol., 106, 661-676, 1988.

D'Arcy, M., Whittaker, A. C., and Roda-Bolduda, D. C.: Measuring alluvial fan sensitivity to past climate changes using a selfsimilarity approach to grain-size fining, Death Valley, California, Sedimentology, 64, 388-424, 2017.

Dietrich, W. E., Kirchner, J. W., Hiroshi, I., and Iseya, F.: Sediment supply and the development of the coarse surface layer in gravelbedded rivers, Nature, 340, 215-217, 1989.

Eaton, B. C., Moore, R. D., and Giles, T. R.: Forest fire, bank strength and channel instability: the 'unusual' response of Fishtrap Creek, British Columbia, Earth Surf. Process. Landf., 35, 1167-1183, 2010.

Ferguson, R.: Flow resistance equations for gravel- and boulder- bed streams, Water Resour. Res., 43, W05427, https://doi.org/10.1029/2006WR005422, 2007.

Ferguson, R.: River channel slope, flow resistance, and gravel entrainment thresholds, Water Resour. Res., 48, W05517, https://doi.org/10.1029/2011WR010850, 2012.

Grant, G. E., Swanson, F. J., and Wolman, M. G.: Pattern and origin of stepped-bed morphology in high gradient streams, western Cascades, Oregon, GSA Bull., 102, 340-352, 1990.

Hancock, G. S. and Anderson, B. S.: Numerical modeling of fluvial strath-terrace formation in response to oscillating climate, GSA Bull., 9, 1131-1142, 2002.
Harries, R. M., Kirstein, L. A., Whittaker, A. C., Attal, M., Peralta, S., and Brooke, S.: Evidence for self-similar bedload transport on Andean alluvial fans, Iglesia, basin, South Central Argentina, J. Geophys. Res.-Earth, 123, 2292-2315, 2018.

Hauser, R.: Abhängigkeit von Korngrössen und Flussformen in den Schweizer Alpen, Unpubl. Ms thesis, Univ. Bern, Bern, Switzerland, 64 pp., 2018.

Hey, R. D. and Thorne, C. R.: Stable channels with mobile gravel beds, J. Hydrol. Eng., 112, 671-689, 1986.

Howard, A. D.: Threshold in river regimes, in: Thresholds in geomorphology, edited by: Coates, D. R and Vitek, J. D., Allen and Unwin, Boston, MA, 227-258, 1980.

Huffman, G. J., Adler, R. F., Bolvin, D. T., Gu, G., Nelkin, E. J., Bowman, K. P., and Wolff, D. B.: The TRMM multi-satellite precipitation analysis: Quasi-global, multi-year, combined-sensor precipitation esti- mates at fine scale, J. Hydromet., 8, 38-55, 2007.

Jarrett, R. D.: Hydraulics of high-gradient streams, J. Hydraul. Eng., 110, 1519-1939, 1984

Jerolmack, D. J. and Paola, C.: Shredding of environmental signals by sediment transport, Geophys. Res. Lett., 37, L19401, https://doi.org/10.1029/2010GL044638, 2010.

Johnston, C. E., Andrews, E. D., and Pitlick, J.: In situ determination of particle friction angles of fluvial gravels, Water Resour Res., 34, 2017-2030, 1998.

Kirchner, J. W., Dietrich, W. E., Iseya, F., and Ikeda, H.: The variability of critical shear stress, friction angle, and grain protrusion in water-worked sediments, Sedimentology, 37, 647-672, 1990.

Komar, P. D. and Li, Z.: Pivoting analyses of the selective entrainment of sediments by shape and size with application to gravel threshold, Sedimentology, 33, 425-436, 1986.

Lenzi, M. A., Luca Mao, L., and Comiti, F.: When does bedload transport begin in steep boulder-bed streams?, Hydrol. Process. 20, 3517-3533, 2006.

Lamb, M. P., Dietrich, W. E., and Venditti, J. G.: Is the critical Shields stress for incipient sediment motion dependent on channel bed slope?, J. Geophys. Res., 113, F02008, https://doi.org/10.1029/2007JF000831, 2008.

Litty, C. and Schlunegger, F.: Controls on pebbles' size and shape in streams of the Swiss Alps, J. Geol., 125, 101-112, 2017.

Litty, C., Duller, R., and Schlunegger, F.: Paleohydraulic reconstruction of a 40 ka-old terrace sequence implies that water discharge was larger than today, Earth Surf. Proc. Landf., 41, 884-898, 2016.

Litty, C., Schlunegger, F., and Viveen, W.: Possible threshold controls on sediment grain properties of Peruvian coastal river basins, Earth Surf. Dynam., 5, 571-583, https://doi.org/10.5194/esurf-5-571-2017, 2017.

MacKenzie, L. and Eaton, B. C.: Large grains matter: constraining bed stability and morphodynamics during two nearly identical experiments, Earth Surf. Proc. Landf., 42, 1287-1295, 2017.

MacKenzie, L., Eaton, B. C. and Church, M.: Breaking from the average: Why large grains matter in gravel-bed streams, Earth Surf. Proc. Landf., 43, 3190-3196, 2018.

Manning, R.: On the flow of water in open channels and pipes, Trans. Inst. Civil Eng. Ireland, 20, 161-207, 1891.

Meyer-Peter, E. and Müller, R.: Formulas for bedload transport, Proceedings of the 2nd meeting of the Int. Assoc. Hydraul Struct. Res., Stockholm, Sweden, Appendix 2, 39-64, 1948. 
Miller, M. C., McCave, I. N., and Komar, P. D.: Threshold of sediment motion under unidirectional currents, Sedimentology, 24, 507-527, 1977.

Mueller, E. R., Pitlick, J., and Nelson, J. M.: Variation in the reference Shields stress for bed load transport in gravelbed streams and rivers, Water Res. Res., 41, W04006, https://doi.org/10.1029/2004WR003692, 2005.

Norton, K. P., Schlunegger, F., and Litty, C.: On the potential for regolith control of fluvial terrace formation in semi-arid escarpments, Earth Surf. Dynam., 4, 147-157, https://doi.org/10.5194/esurf-4-147-2016, 2016.

Paola, C. and Mohring, D.: Palaeohydraulics revisted: palaeoslope estimation in coarse-grained braided rivers, Basin Res., 8, $243-$ 254, 1996.

Paola, C., Heller, P. L., and Angevine, C.: The large-scale dyanmics of grain size variation in alluvial basins, 1: Theory, Basin Res., 4, 73-90, 1992.

Parker, G., Surface-based bedload transport relation for gravel rivers, J. Hydraul. Res., 28, 417-436, 1990.

Pfeiffer, A. M., Finnegan, N. J., and Willenbring, J. K.: Sediment supply controls equilibrium channel geometry in gravel rivers, $\mathrm{P}$. Natl. Acad. Sci. USA, 114, 3346-3351, 2017.

Pfeiffer, A. M. and Finnegan, N. J.: Regional variation in gravel riverbed mobility, controlled by hydrological regime and sediment supply, Geophys. Res. Lett., 45, 3097-3106, 2018.

Powell, M. D., Ockleford, A., Rice, S. P., Hillier, J. K., Nguyen, T., Reid, I., Tate, N. J., and Ackerley, D.: Structural properties of mobile armors formed at different flow strengths in gravel-bed rivers, J. Gephys. Res.-Earth, 121, 1494-1515, 2016.

Reber, R., Delunel, R., Schlunegger, F., Litty, C., Madella, A., Akcar, N., and Christl, M.: Environmental controls on 10Be-based catchment-averaged denudation rates along the western margin of the Peruvian Andes, Terra Nova, 29, 282-293, 2017.

Turowski, J. M., Badoux, A., and Rickenmann, D.: Start and end of bedload transport in gravel-bed streams, Geophys. Res. Lett., 38, L04401, https://doi.org/10.1029/2010GL046558, 2011.
Schlunegger, F. and Garefalakis, P.: Clast imbrication in coarsegrained mountain streams and stratigraphic archives as indicator of deposition in upper flow regime conditions, Earth Surf. Dynam., 6, 743-761, https://doi.org/10.5194/esurf-6-743-2018, 2018.

Sear, D. A.: Sediment transport processes in pool-riffle sequences, Earth Surf. Process. Landf., 21, 241-262, 1996.

Shields A.: Anwendung der Ahnlichkeitsmekanik und der Turbulenzforschung auf die Geschiebebewegung, Mitt. Preuss. Versuch. Wasserbau Schiffbau, Berlin, 26 pp., 1936.

Slingerland, R., Harbaugh, J., and Furlong, K.: Simulating clastic sedimentary basins. Prentice-Hall, Engelwood Cliffs, New Jersey, 220 pp., 1993.

Torizzo, M. and Pitlick, J.: Magnitude-frequency of bed load transport in mountain streams in Colorado, J. Hydrol., 290, 137-151, 2004.

Tucker, G. and Slingerland, R.: Drainage basin responses to climate change, Water Res. Res, 33, 2031-2047, 1997.

Van den Berg, F. and Schlunegger, F.: Alluvial cover dynamics in response to floods of various magnitudes: The effect of the release of glaciogenic material in a Swiss Alpine catchment, Geomorphology, 141-142, 112-133, 2012.

Watkins, S., Whittaker, A. C., Bell, R. E., Brooke, S. A. S., Ganti, V., Gawthrope, R. L., McNeill, L. C., and Nixon, C. W.: Straight from the source's mouth: Controls on field-constrained sediment export across the entire active Corinth rift, central Creece, Basin Res., in press., https://doi.org/10.111/bre.12444, 2020.

Whittaker, A. C., Duller, R. A., Springett, J., Smithells, R. A., Whitchurch, A. L., and Allen, P. A.: Decoding downstream trends in straigraphic grain size as a function of tectonic subsidence and sediment supply, GSA Bull., 123, 1363-1382, 2011.

Wickert, A. D. and Schildgen, T. F.: Long-profile evolution of transport-limited gravel-bed rivers, Earth Surf. Dynam., 7, 1743, https://doi.org/10.5194/esurf-7-17-2019, 2019.

Wolman, M. G.: A method of sampling coarse riverbed material, Eos Trans AGU, 35, 951-956, 1954. 